\title{
RELATIONSHIP BETWEEN ORGANIZATIONAL INTELLIGENCE AND INNOVATIONS: CASE OF LITHUANIAN SPORTS FEDERATIONS
}

\author{
Inga Staškevičiūtè-Butienė, Irena Valantinè, Edvinas Eimontas \\ Lithuanian Sports University, Kaunas, Lithuania
}

\begin{abstract}
Background. Sports organizations exist to perform tasks that can only be executed through cooperative effort, and sports management is responsible for the performance and success of these organizations. The main problem concerning sports organizations and making them implement modern management paradigms is the duality of functions, which divides a sports organization into units increasing the internal competition and reducing the possibilities to create new knowledge. This undoubtedly affects the insufficiently productive functioning of a sports organization under modern conditions of globalization. Organizational intelligence (OI) could be a way to promote innovations, create and share knowledge (McMaster, 1998; Winand, Qualizza, Vos, Zintz, \& Scheerder, 2013b).

Methods. Two questionnaires were used in this research: first, regarding the evaluation of organizational intelligence level, the second regarding the sports organization's preparation for innovations.

Results. One of the lowest evaluated OI factors was organizational openness and the highest rating was given to group work. Comparing OI internal dimensions score of sports organizations which implemented or not innovations during the last 12 months it became clear that there was a significant difference in the scores for organizational openness in sport organizations which implemented innovations and $(M=4.2747, S D=0.82337)$ and for sport organizations which did not implement innovations $(M=3.5874, S D=0.51288), p=.24$ (two-tailed).

Conclusion. Sports organizations having more features of intelligent organization more analyse innovation development opportunities in various aspects, but the level of intelligence and innovation ideas development has no relation, except for costs analysis. Sports organization becoming intelligent and developing innovations had advantage only in some phases of innovation development: situation analysis and decision making.
\end{abstract}

Keywords: sport federations, organizational culture, readiness to innovation process.

\section{INTRODUCTION}

A very interesting case of the global function system in the world society is the global system of sports, which only appeared late in the 19th century society. The global sports system involves the mechanisms of production, experience and consumption. Achievement sport involves the identification and development of talent, its production on a global stage, in a single or multi-sport event and its consumption by direct spectators or, through the media complex, a global mass audience. Over time, there has been a tendency towards the emergence of global achievement sport monoculture - a culture where administrators, coaches and teachers promote and foster achievement sport values and ideologies and where competitions and tournaments are structured along highly co-modified and rationalized lines (Maguire, 2009).

Sports organizations exist to provide sport products and services in the sports industry (Chelladurai, 2005). One critical difference between sports organizations and business organizations is the way they measure performance (Smith \& Stewort, 1999). The main purpose of business 
organizations is to make a profit. Sports governing bodies is a sports organization whose primary goal is to promote and develop sports at all levels in a given territory and sports discipline. This entails control and supervision of a sport, guaranteeing periodic competition at national and international levels, amateur and professional, and from grassroots to senior categories. Another type of sports organization is the one whose main activity is associated with the production of sports events. The operations and activities of these organizations are subordinated to the venue and rules of sports governing bodies, as well professional teams. The main activity of these sports organizations is to design a competition system articulating the interests of all the actors in order to create an attractive sports event. The third type of sports organization in the classification is the one we call the sports providing entity the main activity of which is to design and deliver sports programs for a given community such as clubs, local sport programs, fitness centres, and university sports programs (Gomez, Opazo, \& Marti, 2008). These are private, non-profit associations, dedicated to the provision of recreational sports activities at a local level.

Sports organizations exist to perform tasks that can only be executed through cooperative effort, and sports management is responsible for the performance and success of these organizations. With so many options now available to the sports consumer, it is no longer enough for a sport organization to be simply managed well. To compete and succeed in today's environment, the challenge for every sport organization is to be better. Sports federations are being encouraged to adapt themselves to the expectations of their stakeholders and individual members' satisfaction and attraction of new members represent major goals. Given the growing number of commercial sports providers and the popularity of non-organized sports activities (Vos et al., 2012), it is crucial for sports federations to implement new services to retain and attract members. Achieving new standards (to increase the quality of the products and services, speed and flexibility in responding to customers, to innovate and constantly provide new products and services) is important for different types of sport organizations. The main problem concerning sports organizations and making them implement modern management paradigms is the duality of functions, which divides a sports organization into units increasing the internal competition and reducing the possibilities to create new knowledge. This undoubtedly affects the insufficiently productive functioning of the sports organization under modern conditions of globalization.

According to the approach of constant development, when the architecture of a sports organization is purposefully transformed, it becomes possible to develop the internal dimensions of the organization expediently, aiming to create an intelligent sports organization. An intelligent sports organization should act as a system where collaborative decisions are made, the co-workers show initiative and the ability to make teams unreservedly; such organization should allow a degree of decentralization which promotes organizational learning and integrating processes; sports organization should also be able to generate knowledge and use it when it adapts to the environment.

Scientific literature suggests different conceptions of organizational intelligence, but all of them are united by one common feature: organization's ability to adapt to the changing environment together with knowledge management, as OI encompasses competition based on knowledge, which is common to an organization. This competition is the basis to success of a knowledge organization in the rapidly changing and competitive environment. The profound analysis of research literature let us conclude that OI can be perceived as a certain way of organizing organizational activities which emerge organizational culture and become an inseparable part of it.

The formation of OI directly depends on the number of creative, innovative and initiative employees in the organization and their ability to communicate among themselves; the heads of the organization must be discontent with the present situation and constantly look for ways to act more effectively; organizational culture must reflect the values of each employee: orientation to the problems and changes, initiative, taking risk. When knowledge is successfully integrated in the organization, every worker in the organization perceives how all kinds of work are done in the organization; managers and workers' perceptions about the roles, responsibilities and methods in the organization coincide; it is not difficult to identify and eliminate drawbacks impeding success, good experience is quickly identified and implemented in practice, and knowledge integration ensures feedback in all the hierarchical layers. 
In the theoretical analysis of managing intelligent organizations, most attention was paid to the analysis of the conceptions of management and leadership, and organizational leadership as a resource. Different organizational models suggest different management styles, thus, when we spoke about organizational management, we paid most attention to indirect management. Three main systems in indirect management were distinguished - delegating in the hierarchical structure; creating a community with a common goal and values; and implementing the system of free market. In the management of an intelligent organization we distinguished and discussed three main theories: 1) transformational leadership (Tsoukas \& Vladimirou, 2005), 2) intelligent leadership (Sydanmaanlakka, 2002), and 3) connected leadership (Gobillot, 2007). Managing intelligent organizations means not only administration functions, which are also important, but also engaging workers into the organizational management processes, motivating them, creating the sense of community, providing freedom in decision making, innovations, learning and knowledge creation.

It can be stated that OI refers to its created value - the improvement of the effectiveness of its activities. Activities of any organization are directed towards the achievement of results, which are expressed as aims, vision and mission. Modern management applies various indices of the evaluation of organizational effectiveness. The effectiveness of activities of sports organizations cannot be linked with the increase of profit because the aims of sports organizations deal with meeting the needs of the community. Thus, the notion of intelligence of sports organizations is different because they are conditioned by the social needs and attitudes despite their effort to compare to business organizations.

Knowledge and skills become valuable only when they are used in certain purposeful activities. In the society of science there is an increase of interest in the recognition, mobilization and formalization of employees' knowledge in order to promote innovations and competitive ability. There is much of research about innovations, but there is still a lack of studies about innovation development in sports organizations such as non-profit sports organizations (various sports federations or associations). Many academic articles could be found under the topic of innovations in basic organizational context (Crossan \& Apaydin, 2010).
Researchers have pointed out that innovation is a source of competitive advantage, in the public, private, and non-profit sectors, through improved effectiveness and efficiency (Damanpour \& Aravind, 2012; Dess \& Picken, 2000; Lee, Ginn, \& Naylor, 2009; McDonald \& Srinivasan, 2004). The for-profit sector is often seen as the most dynamic sector of sports market as competition leads to innovation (Gratton \& Taylor, 2000; Robinson, Hewitt \& Harris, 2000). Non-profit sport organizations (NPSOs), such as voluntary sports clubs or sports federations, are encouraged to change to satisfy and meet new expectations of their members. Indeed, their ability to innovate is just as important as for other organizations (Newell \& Swan, 1995), in part because of the growing commercialization and professionalization of sports industry. That competition, as perceived by the management board, leads NPSOs to innovate (Winand, Qualizza, Vos, Zintz, \& Scheerder, 2013a). Sports federations compete for financial support, sports results, and membership participation (Newell \& Swan, 1995). Sports federations innovate to attract and retain members (Newell \& Swan, 1995; Thibault, Slack, \& Hinings, 1993) and might develop an attitude favouring innovation to cope with their competitive environment. This type of sports federations would be more innovative (Winand et al., 2013b).

Organizational intelligence could be a way to promote innovations, create and share knowledge. At the beginning most authors (March, 1999; McMaster, 1998) compared organizational intelligence to information/data management by means of informational technologies, but lately researchers (Farrel, 2007) view this management paradigm as an absolutely new means of organizational management which involves all the processes (organizational openness, formality, knowledge creation and management, group work, organizational learning, leadership expression, systemic thinking) on the plane of internal dimensions.

Very few studies have paid attention to the notion of innovation in NPSOs (except for Caza, 2000; L. Hoeber \& O. Hoeber, 2012; Newell \& Swan, 1995), and none of them have developed a conceptualization of innovation in NPSOs, which could form the basis for further research.

Research question: Are sports organizations prepared for the development of innovations and how it relates to organizational intelligence. 


\section{METHOD}

Procedure and sample representatives. The data was collected by web-based survey conducted in various sports federations of Lithuania in MarchMay, 2015. Each questionnaire was completed by the all personnel of sports organizations.

Overall, the questionnaire was sent to a total number of 75 sports organizations of 80 sports federations of Lithuania. Having official permission, the questionnaires were distributed via employees' emails aiming to increase the accessibility of the respondents. Thus, we can claim that inside a sport organization the questionnaires were distributed to all employees irrespective of their positions. The response rate was $60 \%$ in each sports organization. The relatively low response rate can be explained by the great extent of the questionnaire, which required much time to fill it in taking into account the size of the questionnaire (more than 200 questions), the response rate must be regarded as satisfactory.

Questionnaire. In relation to the topic of this paper, two batteries with questions were relevant. First, one battery included 148 questions regarding the evaluation of organizational intelligence level in sports organizations (Staskeviciute, 2009). An original research methodology was created comprising 146 rank scale questions. Participants of the research had to respond on a seven-point Likert scale ranging from "I absolutely do not agree" to "I absolutely agree".

The second battery included 23 questions regarding the sports organization's preparation for innovations. The research instrumentation was formed on the principle of individual diagnostic blocks, derived from the theoretical analysis and research to determine the desired components: an innovative service development process (described as NuServ model by Shekar, 2007). The background variables included in this study are: size and type of organization, the position in organization.

The internal reliability of organizational intelligence instrument was computed by using Cronbach's alpha rate. The rate of the constructed questionnaire was .977. It can be stated that the internal reliability of this questionnaire was high - the questions were interrelated and they measured the same phenomenon. The devised instrument for the evaluation of the development of the organization in the context of an intelligent organization allowed evaluating the degree of internal organizational dimensions and foreseeing the direction of its development.
Data analysis. The statistical analysis was performed using the statistical software SPSS version 17.0. The methods of analysis included Cronbach's alpha coefficients, descriptive statistics, Pearson's correlations, and Student's $t$-test. Statistical significance was set at $p<.05$ for all tests.

\section{RESULTS}

The results are presented in two sections: first, the analysis of sports organizations' organizational intelligence; second, the relationship between organizational intelligence and intentions to innovate.

Organizational intelligence. The analysis of the survey results showed that the Lithuanian sports organizations' OI differed $-52 \%$ of all organizations involved in the study had an average level of organizational intelligence.

The analysis of each factor separately showed that the assessment of each range from 3.9 to 4.16 points. One of the lowest evaluated OI factors was organizational openness (average score -3.9 out of 6 points). The highest rating is group work (4.16 out of 6 points) (Figure 1).

Analysing the relationship between organizational openness sub-factors, it appeared that employees were likely to miss important deadlines and the use of the phrase "I do not know" is used in the absence of the climate of confidence between workers and direct manager (correlation coefficient .609 and .630 at the significance level of .05). If the leaders of the organization were able to listen and hear, the cooperation between employees was much more efficient (correlation coefficient .733 at the significance level of .05). The employees of sports organizations believed that direct manager trusted them when they presented their plans, results, involved them in the decision-making process (correlation coefficient .772 at the significance level of .05). Thus, the results of the study revealed that the openness of sports organizations was dependent on the attitude of the direct manager to the employees and their behaviour.

The study of organizational formality factors revealed that in compliance with the sports organization's priorities, rules and regulations, the information channels within the organization operates more efficiently (correlation coefficient .752 at the significance level of .05), decisions were taken in meetings (correlation coefficient .837 at the significance level of .05). The study also revealed that in a significant and compelling vision, the 


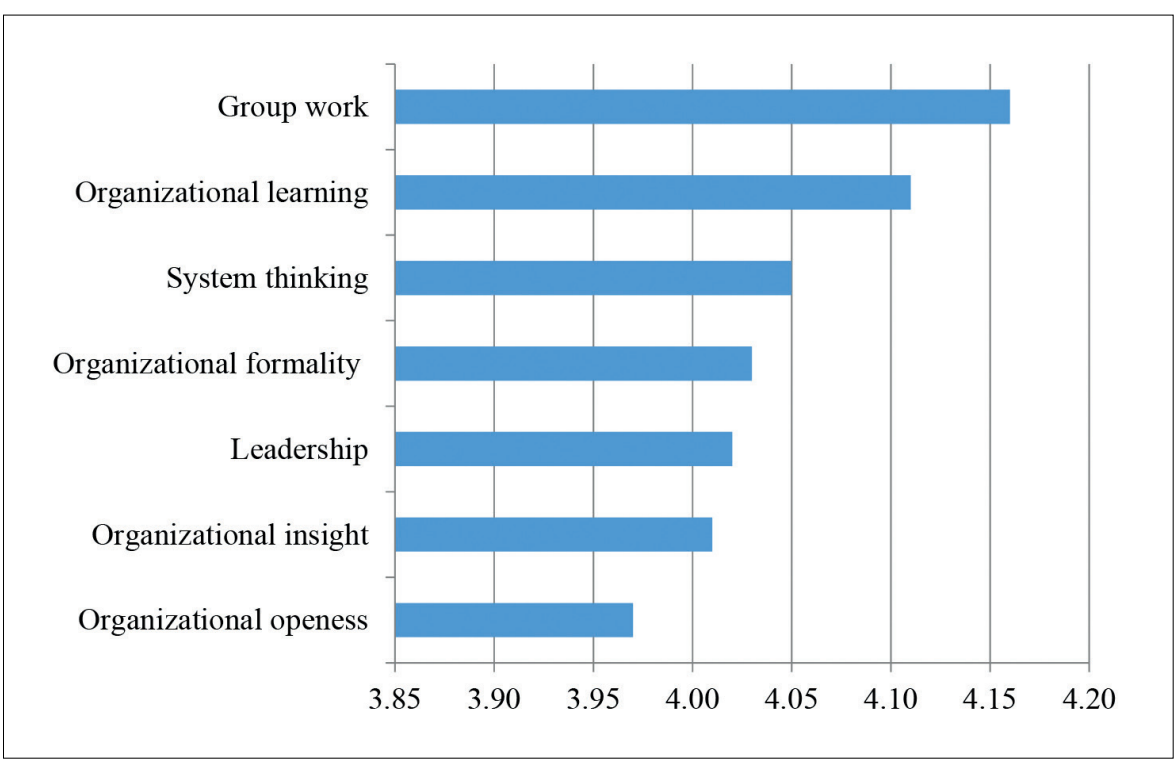

Figure 1. The evaluation of $\mathrm{OI}$ factors

current organizational structure supported strategic initiatives (correlation coefficient .847 at the significance level of .05). Every sports organization employee was encouraged to introduce new methods if the direct manager was willing to help solve problems (correlation coefficient .821 at the significance level of .05).

The study data showed that if every employee believed that their suggestion and opinion would be heard and taken into account then the overall quality of the organization's work was seen as high (correlation coefficient .789 at the significance level of .05). The organization preferred to measure its success by the human resource development, teamwork and dedication of staff if the staff involved in the development and review of the strategy (correlation coefficient .714 at the significance level of .05).

If the direct manager perceived knowledge and learning as key resources and professional skills showing them respect and recognition, it activated the natural cultural process in which people shared knowledge and other relevant information (correlation coefficient .707 at the significance level of .05). Problem solving was based on the involvement of employees if the head of the organization perceived knowledge and learning as key resources and professional skills showing them respect and recognition (correlation coefficient .730 at the significance level of .05). If the direct manager was willing to admit their mistakes and undo the steps that were not effective and beneficial, when they supported and encouraged openness, making changes and the atmosphere of new ways of thinking (correlation coefficient .729 at the significance level of .05).
If the organization regularly examined the implemented changes and their results, then it was likely that the organization had the organizational performance, employee performance and etc. evaluation systems (correlation coefficient .716 at the significance level of .05) and it showed that direct managers were more likely to trust their employees (correlation coefficient .716 at the significance level of .05). If there was cooperation between direct managers and employees, then cooperation among the staff was much more efficient (correlation coefficient .850 at the significance level of .05 ). If the head of the organization together with the employees took responsibility for risky decisions made and the consequences of the change, the direct manager was more likely to ask the staff for their opinion (correlation coefficient .822 at the significance level of .05).

Every staff member felt that their contribution had an impact on the success of the organization if they received feedback on their work performance and contribution to the recognition and respect of the organization's expectations (correlation coefficient .800 at the significance level of .05). If every employee in an organization expressed a sense of belonging, then the work atmosphere encouraged them to learn from their mistakes (correlation coefficient .726 at the significance level of .05) and their leaders deliberately trying to inform employees (correlation coefficient .701 at the significance level of .05).

If an organization had an effective planning, each employee was willing to accept and implement changes (correlation coefficient .775 at the significance level of .05). If the direct manager 
presented plans, priorities and results to the employees, then each employee was ready to help the organization to achieve its goals (correlation coefficient .748 at the significance level of .05). If there was a reliance on the decisions of the employees, then the head of the organization created an atmosphere in which employees were motivated (correlation coefficient .706 at the significance level of .05). In a clear distribution of authority and responsibility, more frequent conversations were about the environment and how to overcome frequent challenges (correlation coefficient .771 at the significance level of .05).

The relationship between organizational intelligence and intentions to innovate. Fifty six percent of respondents in last 12 months implemented innovations or planned to do so. The comparison of sports organizations OI levels by intentions to innovations is shown in Figure 2.

An independent samples $t$-test was conducted to compare the OI scores for sports organizations which implemented or not innovations during the last 12 months. There was no significant difference in the scores for sports organizations which implemented innovations $(M=4.2357, S D=0.61470)$ and for sports organizations, which did not implement innovations $(M=3.7909, S D=0.59909), p=.82$ (two-tailed).

Comparing the scores of organizational intelligence factors by an independent samples $t$-test in the sport organizations which implemented or not innovations during the last 12 months, it became clear that there was a significant difference in the scores for organizational openness in sports organizations which implemented innovations and $(M=42747, S D=0.82337)$ and for sports organizations which did not implement innovations $(M=$ 3.5874, $S D=0.51288), p=.24$ two-tailed). Also, there was a significant difference in the scores for organizational insight in sports organizations which implemented innovations $(M=4.2313, S D=$ 0.60172 ) and for sports organizations which did not implement innovations $(M=3.7186, S D=0.51528)$, $p=.34$ (two-tailed).

Correlation of intent to innovate and the level of organizational openness (correlation coefficient .450 at the significance level of .05) and organizational insight (correlation coefficient .425 at the significance level of .05) of organizational intelligence showed causality of medium strength. Significance and correlation coefficient had medium strength and showed tendencies: a) the more organization was open, the more they thought about innovations and their implementation; and b) the more organization showed internal insight, the more they thought about innovations and their implementation.

The results of the research revealed that the level of organization's group work correlated with the aim to develop innovations corresponding to sports organization's aims and vision (correlation coefficient $.767, p=.01$ ). This means that when organization values group work, i.e. group efforts, it will more seek to develop innovations according to the vision and aims. Sports organization which is open to the environment and has organizational learning features more researches the environment aiming to identify innovation opportunities (cor-
Figure 2. The relationship between $O I$ and intentions to innovate

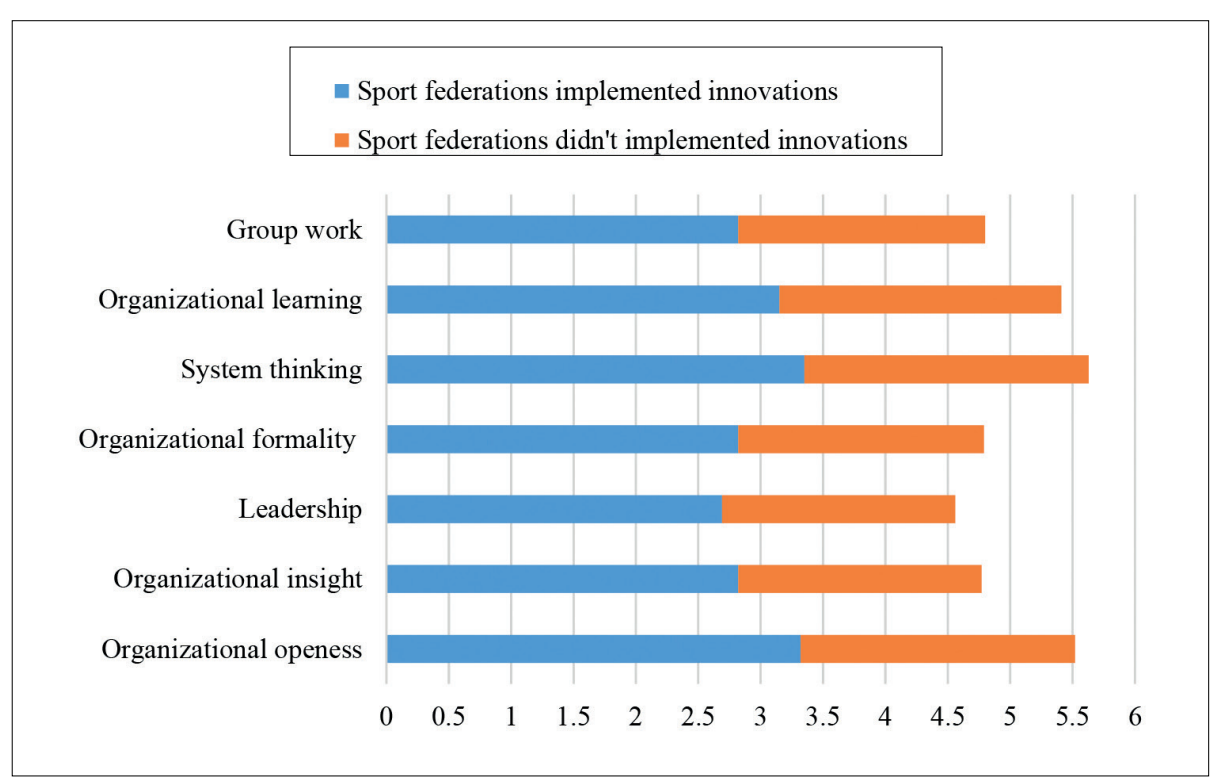


Table 1. Correlation matrix: preparation for innovations vs OI

\begin{tabular}{|c|c|c|c|c|c|c|c|c|}
\hline \multicolumn{2}{|r|}{ Variables } & 言 & ב⿱艹 & 蛋 & ב⿱艹 & ב⿱艹 & $\cong$ & క్ \\
\hline \multirow{4}{*}{ 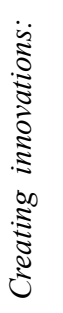 } & Checking whether there is enough information & .758 & .785 & & & .716 & .817 & 846 \\
\hline & Analysing the global market situation & .801 & .872 & & .758 & .824 & .859 & .836 \\
\hline & Analysing the internal data of the company & & .745 & 0.851 & & & .747 & \\
\hline & Analysing the market & .811 & .756 & & & .757 & .830 & .822 \\
\hline \multicolumn{2}{|r|}{$\begin{array}{l}\text { Innovation development is often influenced by the situation in the } \\
\text { external environment }\end{array}$} & & .768 & & & & .780 & .778 \\
\hline \multicolumn{2}{|r|}{$\begin{array}{l}\text { Always performing analysis of the demand before implementing } \\
\text { the innovations }\end{array}$} & 769 & .730 & & .739 & .810 & .804 & .791 \\
\hline \multicolumn{2}{|r|}{$\begin{array}{l}\text { Always calculating a preliminary investment required for the } \\
\text { development before implementing the innovation }\end{array}$} & .725 & .850 & & .759 & .830 & .831 & .787 \\
\hline \multicolumn{2}{|r|}{$\begin{array}{l}\text { Always performing target market analysis, anticipating } \\
\text { innovations, consumer groups before implementing the } \\
\text { innovation }\end{array}$} & .870 & 902 & 0823 & .871 & 930 & .848 & .864 \\
\hline \multicolumn{2}{|r|}{$\begin{array}{l}\text { Generating different ideas and options before creating } \\
\text { innovations }\end{array}$} & .716 & .702 & & & & .767 & .746 \\
\hline \multicolumn{2}{|r|}{ Creating innovations accurately describing their conception } & & .752 & & & & .770 & .748 \\
\hline
\end{tabular}

Note. $* p=.01$.

relation coefficients .811 and $.739, p=.01$ and $p=.03$ ). Organization's formal level correlates with the investments needed for the evaluation of innovations (correlation coefficient .850, $p=.000)$. Research results also revealed that sports organizations having more features of intelligent organization more analysed innovation development opportunities in various aspects, but the level of intelligence and the development of innovation ideas had no relation, except for costs analysis. The choice of innovation concept and development had a direct relation with the intelligent organization features, especially systematic thinking and openness, when customers' attitudes had an impact on the choice of innovations.

\section{DISCUSSION}

The results revealed that Lithuanian sports organizations were not sufficiently well prepared for modern management methods and challenges of globalization. The lowest level of openness estimate showed that the dissemination of information within the sports organization was limited, although it is necessary to draw attention to the fact that the majority of the Lithuanian sports organizations can be classified as small and very small organizations. The results of the study revealed that the limited capacity of the relevant internal information reduced possibilities for sports organizations to become a learning organization. The current limited capacity of the internal information was closely related with the strategy of leadership: the example of the leaders was determined by a number of behavioural changes among employees who fostered better information sharing and reducing internal competition. The results show that sports organizations in Lithuania were more focused on the formal processes using contacts of the hierarchical organizational structure, acting in accordance with established rules and procedures. It is important to note that only the current match between the declared and actual operating rules is effective and encouraging employee involvement in the organization's activities and decision-making process.

Teamwork level has direct links with sports organizations in the common assessment of quality: the more frequently group work method is used, the more positively the quality of sports organization 
is evaluated. Accordingly, the involvement of employees in the decision-making process suggests that the success of an organization is more often seen as a result of teamwork. It should be noted that teamwork was given the highest scores by Lithuanian sports organizations, which can be evaluated as a strong point, but due to the limited internal dissemination of information this factor does not allow creating a learning organization. The behaviour and attitudes of employees towards the head of the organization is significant for organizational learning. The results of the study showed quite favourable conditions from the heads of the organization for the organizational learning in the Lithuanian sports organizations, but the existing framework of openness and the level of formality did not facilitate and encourage the creation of new knowledge and the sharing of the information available.

Although the results of the study revealed that systemic thinking was higher than the average level in Lithuanian sports organizations, it was more related to the loyalty and dedication to the organization rather than the ability to collectively reach the insights necessary for the success of sports organizations for further action, providing the potential challenges.

Accordingly, processes and organizational systems of an intelligent sports organization influenced by intelligent processes create an effect of synergy, which becomes an advantage of an intelligent sports organization while competing in the global market. Intelligent decisions made and their implementation together with intelligence processes create value, the expression of which is qualitative and quantitative indicators of sports organization's activities and the improvement of its activities, as well as tangible and intangible resources.

Organizational intelligence becomes significant not only at different levels of the organization, but also in the relationship of the organization with its environment and the parties concerned. The theoretical preconditions suggest that the changes in the conceptions of organizational management and activity processes enabled identifying transformations in organizational intelligence which affected its evolution and specificity of activities.

The analysis of factors influencing success of sports organizations in the theoretical part let us claim that those factors affected the transformations and analysis of organizational activities allowing effective adaptation to the rapidly changing environment implementing strategic aims. The changes in the environment encourage sports organizations to review their management methods and modernize them if they want to remain or compete in the global market and to create its longterm advantage. The main problem concerning the organizations and making them implement modern management paradigms is the duality of functions, which divides the organization into units increasing the internal competition and reducing the possibilities to create new knowledge. This undoubtedly affects the insufficiently productive functioning of the organization under modern conditions of globalization.

Research results also show that there is a strong and moderate correlation between the groups of factors in the components of organizational intelligence, and between different components of it. The existence of the cause relation allows a more purposeful and systematic development of internal organizational dimensions. The transformations in the development of the internal dimensions of intelligent organizations become possible only after the evaluation of the level of internal dimensions in respect to an intelligent organization.

The empirical results of the research showed that among the intelligence components of the organizational strength of different causal relationships - affecting a particular component of the organizational intelligence - changing its internal quality levels, respectively, just some of the other organizational components of the inner dimensions of intelligence. In the development of intelligent organization it is necessary to evaluate the internal dimensions of independent existence, and their inclusion in the development of organizational intelligence.

The level of organization's group work correlates with the aim to develop innovations corresponding sports organization's aims and vision. Sports organization which is open to the environment and has organizational learning features more often researches the environment aiming to identify innovation opportunities.

Sports federations whose staff favours novelty are significantly more innovative and develop different types of service innovation. These types include leisure sports activities for adults, training programmes as well as club management support. In line with previous research in other contexts (Damanpour, 1991; Damanpout \& Aravind, 2012; Damanpour \& Schneider, 2009), the study of 
Winand, Qualizza, Vos, Zintz, and Scheerder (2013b) demonstrated that attitudes favouring the introduction of new knowledge within NPSOs were critical to the level of innovativeness. The sports characteristics managed by sports federations influence preferences in knowledge creation/ appropriation, and ultimately the type of innovation developed (Winand et al., 2015). In line with Bierly, Damanpour, and Santoro (2009), some sports federations might be inclined to develop similar types of innovation over time and organizational characteristics influence preferences in knowledge creation/appropriation, and the type of innovation non-profit sports organizations develop.

\section{CONCLUSIONS}

Diagnosis of the current situation in sports organizations according to organizational intelligence components, so that organizations could make decisions about their further development or the maintenance of the current level of the organization.

The backgrounds of the formation of organizational intelligence are: 1) the formation of organizational intelligence directly depends on the number of creative, innovative and initiative employees in the organization and their ability to communicate among themselves; 2) the heads of the organization must be discontent with the present situation and constantly look for ways to act more effectively; 3) organizational intelligence is more common to those organizations which exist in the turbulent environment; 4) organizational culture must reflect the values of each employee: orientation to the problems and changes, initiative, taking risk.

Developing an intelligent organization, it is necessary to know the current situation because the interaction of the components of intelligent organization creates a synergetic effect.

Sports organizations having more features of intelligent organization more analyse innovation development opportunities in various aspects, but the level of intelligence and innovation ideas development has no relation, except costs analysis. Sports organization becoming an intelligent sports organization and developing innovations had an advantage only in some phases of innovation development: situation analysis and decision making.

\section{REFERENCES}

Bierly, P., Damanpour, F., \& Santoro, M. (2009). The application of external knowledge: Organizational conditions for exploration and exploitation. Journal of Management Studies, 46, 481-509. doi: 10.1111/j.14676486.2009.00829.x

Caza, A. (2000). Context receptivity: Innovation in an amateur sport organization. Journal of Sport Management, 14(3), 227-242.

Chelladurai, P. (2005). Managing organisations for sport and physical activity. Scottsdale Arizona: Holcomb Hathaway Publishers.

Crossan, M. M., \& Apaydin, M. (2010). A multi-dimensional framework of organizational innovations: Systematic review of the literature. Journal of $\mathrm{Ma}$ nagement Studies, 47, 1154-1191. doi:10.1111/j.14676486.2009.00880.x

Damanpour, F., \& Aravind, D. (2012). Organizational structure and innovation revisited: From organic to ambidextrous structure. In M. Mumford (Ed.), Handbook of organizational creativity (pp. 479-509). London: Elsevier.

Damanpour, F. (1991). Organizational innovation: A meta-analysis of effects of determinants and moderators. Academy of Management Journal, 34, 555-590. doi: $10.2307 / 256406$

Damanpour, F., \& Schneider, M. (2009). Characteristics of innovation and innovation adoption in public organi- zations: Assessing the role of managers. Journal of Public Administration Research and Theory, 19, 495-522. doi:10.1093/jopart/mun021

Dess, G. G., \& Picken, J. C. (2000). Changing roles: Leadership in the 21 st century. Organizational Dynamics, 28(3), 18-34. doi:10.1016/s0090-2616(00)88447-8

Gratton, C., \& Taylor, P. (2000). Economics of sport and recreation. London: Spon Press

Gobillot, E. (2007). The connected leader. Creating agile organizations for people, performance and profit. London and Philadelphia: Kogan Page.

Gomez, S., Opazo, M., \& Marti, C. (2007). Structural characteristics of sport organizations: main trends in the academic discussion (Working Paper WP-704). IESE Business School, University of Navarra.

Hoeber, L., \& Hoeber, O. (2012). Determinants of an innovation process: A case study of technological innovation in a community sport organization. Journal of Sport Management, 26(3), 213-223.

Lee, R. P., Ginn, G. O., Naylor, G. (2009). The impact of network and environmental factors on service innovativeness. Journal of Services Marketing, 23(6), 397-406. doi: 10.1108/08876040910988183

Maguire, J. (2009). Sport and Globalization. Retrieved from http://assets.sportanddev.org/downloads/81_sport_ and_globalisation.pdf

March, J. G. (1999). Exploration and exploitation in organizational learning. Organization Science, 2, 71-87. 
McDonald, R. E., \& Srinivasan, N. (2004). Technological innovations in hospitals: What kind of competitive advantage does adoption lead to? International Journal of Technology Management, 28(1), 103-117. doi: 10.1504/IJTM.2004.005055

McMaster, M. D. (1998). Organizational Intelligence. Knowledge Based Development. The Industrial Society. Retrieved from htpp://www.kbdworld.demon.co.uk/ articles/indsoc.

Newell, S., \& Swan, J. (1995). The diffusion of innovations in sport organizations: An evaluative framework. Journal of Sport Management, 9(3), 317333.

Robinson, D., Hewitt, T., \& Harris, J. (2000). Why interorganisational relationships matter. In D. Robinson, T. Hewitt, and J. Harris (eds.), Managing Development: Understanding Inter-organizational Relationships (pp. 1-16). London: Sage Publications.

Shekar, A. (2007). An innovative model of service development: A process guide for service managers. The Public Sector Innovation Journal, 12(1), 1-18.

Staskeviciute, I. (2009). Development of intelligent organization in the context of internal organizational dimensions transformations (Doctoral dissertation). Kaunas: Kaunas University of Technology.
Sydanmaanlakka, P. (2002). An intelligent organization. Integrating performance, competence and knowledge management. London: Capstone.

Thibault, L., Slack, T., \& Hinings, B. (1993). A framework for the analysis of strategy in non-profit sport organizations. Journal of Sport Management, 7(1), 25-43.

Tsoukas H., \& Vladimirou, E. (2005). Managing knowledge: An essential reader. Sage publications Ltd.

Vos, S., Breesch, D, Késenne, S., Lagae, W., Van Hoecke, J., Vanreusel, B., \& Scheerder, J. (2012). The value of human resources in non-public sports providers. The importance of volunteers in non-profit sports clubs versus professionals in for-profit fitness and health clubs. International Journal of Sport Management and Marketing, 11(1/2), 3-25.

Winand, M., Qualizza, D., Vos, S., Zintz, T., \& Scheerder, J.(2013b). Determinants of service innovation: A typology of sports federations. International Journal of Sport Management and Marketing, 13(1/2), 55-73.

Winand, M., Qualizza, D., Vos, S., Zintz, T., \& Scheerder, J. (2013a). Fédérations sportives innovantes: Attitude, perceptions et champions de l'innovation [Innovative sport 29 federations: Attitude, perceptions and innovation champions]. Revue Interdisciplinaire sur le Management et l'Humanisme, 6, 5-20. 